\title{
The image of mind in the language of children with autism
}

\author{
Wolfram Hinzen 1,2,3*, Joana Rosselló ${ }^{3}$, Otávio Mattos ${ }^{3}, K_{r i s t e n}$ Schroeder $^{3}$ and \\ Elisabet Vila $^{3}$ \\ 1 Institució Catalana de Recerca i Estudis Avançats (ICREA), Barcelona, Spain, ${ }^{2}$ Department of Philosophy, University of \\ Durham, Durham, UK, ${ }^{3}$ Grammar and Cognition Lab, Department of Linguistics, Universitat de Barcelona, Barcelona, Spain
}

Keywords: autism, language, grammar, reference, deixis, pronouns, communication

While it is widely agreed today that autism involves a cognitive change (Baron-Cohen, 1988), the main psychological models have put the explanatory weight on changes in such nonlinguistic neurocognitive variables as "theory of mind" (ToM), weak central coherence, or executive functioning. Linguistic deficits, including ones identified as "pragmatic" and taken to be universal in people with autism spectrum disorders (ASD) (Tager-Flusberg, 1996; Lord and Paul, 1997; TagerFlusberg et al., 2001), or even the absence of functional language could then be seen as a secondary consequence of a primary defect in non-linguistic (particularly social) cognition (Mundy and Markus, 1997). A "modular" perspective, which separates language from cognition, has been widely adopted with regard to the internal organization of language itself, which is taken to comprise phonology, syntax, semantics, and pragmatics as relatively independent components. In this regard, Tager-Flusberg (1981) formulates the classical view that "phonological and syntactic development

OPEN ACCESS

Edited by:

Itziar Laka,

University of the Basque Country UPV/EHU, Spain

Reviewed by:

Aritz Irurtzun,

Centre National de la Recherche Scientifique-IKER (UMR 5478), France

*Correspondence: Wolfram Hinzen, hinzen@ub.edu

Specialty section:

This article was submitted to

Language Sciences,

a section of the journal

Frontiers in Psychology

Received: 27 March 2015

Accepted: 03 June 2015

Published: 18 June 2015

Citation:

Hinzen W, Rosselló J, Mattos O, Schroeder K and Vila E (2015) The image of mind in the language of

children with autism.

Front. Psychol. 6:841

doi: 10.3389/fpsyg.2015.00841 follow the same course as in normal children and in other disordered groups, though at a slowed rate, while semantic and pragmatic functioning may be specially deficient in autism."

More recently, attention was drawn to a potential subtype of ASD, autism with language impairment (ALI), showing deficits in structural aspects of language comparable to those in Specific Language Impairment (SLI) (Tager-Flusberg and Joseph, 2003), additionally to standard impairments in social interaction and communication, and behavioral abnormalities. Specific deficits in such domains as non-word repetition (phonology) or verbal inflection (morphology), as seen in this subtype (Tager-Flusberg, 2006), however, provide little basis for understanding the distinctive ASD cognitive "style" (Happé and Frith, 2009). Indeed the absence of co-morbid non-verbal cognitive impairment is a defining feature of SLI.

Yet it is not clear how independent of language human-specific forms of social interaction and communication can be, and it could be that a fundamental alteration in language competence is an inherent aspect of the cognitive change in question. Children with autism might construe language differently, reflecting a linguistic style different from that inherent in neurotypical cognition, which could then be reflected in altered patterns of social communication. Rapin and Dunn (2003) already suggested, not only that phonology and syntax are impaired in autism, but that there is a relation between phonological and syntactic deficits, and between semantic and pragmatic ones. Kjelgaard and Tager-Flusberg (2001, p. 10) suggest that phonological deficits are only present in those children with higher-order semantic and syntax deficits.

Language could matter in a different way, if it was more than communication-and more even than a human-specific style of communication: It could also be cognition, i.e., a principle for having the particular type of thought that is communicated in language (Hinzen and Sheehan, 2013). It is surely not simply an accident that humans, apart from having the cognitive type that they do, also speak: subtracting our linguistic capacity from our cognitive toolkit does not allow the same mind to develop, though now it is now tragically speechless. Language makes us social in ways that no other species is, allowing us a form of communication in which propositional thoughts can be articulated and shared. A look at the cognitive types and communications of non-linguistic 
species (Hauser, 1996; Penn et al., 2008; Tomasello, 2008), and at the cultural productions of extinct hominins (Tattersall, 2008), suggests an explanatory gap between species with and without a language-like symbolic code. Language remains one of the most likely cognitive principles for explaining what transformed presapiens cognitive phenotypes into their modern human variety, re-configuring the hominin mind rather than merely expressing one that pre-existed the arrival of linguistic communication (Tattersall, 2014). Hinzen and Sheehan (2013) describe the organizational principles of language as those of human-specific thought.

In line with this linguistic model, we also see language playing an intrinsic role in the development of normal thought and communication in infants (Vouloumanos and Waxman, 2014). Where there is no exposure to speech/sign, or language does not develop normally, thought is diminished or altered as well, as in language-less adults (Schaller, 2012), deaf children deprived of a sign language (Humphries et al., 2014), or children with autism, as we argue below. Arguably our relationship to ourselves in general, i.e., our human-specific sense of self, is mediated by language and narrative, in that we canonically refer to ourselves in the grammatical 1st Person ("I"), connecting linguistically to others who are grammatical 2nd Persons for us ("you"). What we say to them in turn carries information about a world viewed as distinct from both of us and the thoughts we share: it is grammatically the 3rd (or non-) Person ("it," "s/he," "that"). This threefold distinction of grammatical Person spans a "deictic space" in which all human thought and communication is anchored or embedded. This space is partially human-specific and Person distinctions are defined in relation to when speech acts take place, making a relation not only to language but to speech/sign inherent. Saying "I" as and when we speak, we locate ourselves in this space, with a past that partially defines us, a future which language helps us to creatively construct, and a personal narrative involving others. We argue in the remainder that a disturbance in this language-mediated deictic frame could play a key role in making sense of the autism cognitive and communicative phenotype, providing a unified linguistic and psychological model.

That language is indeed construed differently in ASD is strongly suggested by the universality of both communicative and pragmatic impairments in the autism spectrum, while the status of repetitive behaviors and interests is more contested (Mandy and Skuse, 2008). It could only be by separating a "pragmatic" or a "communication" impairment from a "language impairment," that the claim of a language impairment in only a subgroup of individuals could be upheld. In general, language and human-specific communication can barely be separated. Our position predicts that language in ASD should not merely be delayed or slowed but altered, in ways that illuminate the cognitive change, and a significant decrease in general syntactic ability across children with ASD as compared with children with developmental delays or mental retardation has now been documented (Pierce and Bartolucci, 1977; Eigsti et al., 2007). In Eigsti et al., 2007, syntactic ability was negatively correlated both with use of jargon/echolalia and with presentism/concretism (lack of displacement). Beyond delayed onset of first words as also present in other disorders, children with ASD can show a deviant pattern of lexical growth (Lord et al., 2004).

As for problems with communication, the problem in ASD does not lie in communication as such-children with ASD can and do communicate-but in the normal forms of linguistic communication (Maljaars et al., 2011). There are basic disturbances in speech production and perception that could have resounding effects in the contents communicated in speech. Alterations in speech perception (Alcantara et al., 2004) and the preference of speech over non-speech (Klin, 1991) have been documented and neurophysiological methods have revealed a "profoundly different stimulus-processing manner in autism" partially specific to sound discrimination in speech (Kujala et al., 2013). Speech (or sign), the vehicle of linguistic communication, which preferentially captures newborn infants' attention from birth (Vouloumanos and Waxman, 2014), does not attract autistic children as much. Typically developing 6-month-old infants grasp the abstract role of speech in communication before having knowledge of words (Vouloumanos et al., 2014), which must further enhance their development, whether of language or thinking. By contrast, even siblings at high risk for ASD at 12 months do not pay the same attention to speech as typically developing children (Curtin and Vouloumanos, 2013). Deficits of prosody are also common (Peppe et al., 2007).

Furthermore, supposedly "non-verbal" aspects of cognitive development such as joint attention or pointing appear to be inherently linked to linguistic development. A tight coupling of declarative pointing and language has been demonstrated in normal children (Cartmill et al., 2014). Mundy et al. (1990), in a longitudinal study of early joint attention and language, found that the former was a significant predictor of the latter in autistic children. Joint attention seems to be crucially enhanced by a bias toward speech already present in newborn infants (Vouloumanos and Waxman, 2014), and it is an ingredient of declarative pointing, which is clearly impaired in ASD. Declarative pointing is co-morbid with a structural change in the deictic use of language more generally, manifest in misuses of such expressions as "here" vs. "there" and "this" vs. "that" (Hobson et al., 2010; Hobson and Meyer, 2005).

Regarding the contents of communication, the normal declarative use of language for the purpose of affirming and sharing thoughts is deviant in verbal children with autism (Loveland et al., 1988). This is neither merely a communicative nor a pragmatic impairment, but also concerns the distribution of linguistic forms: imperatives cannot, in virtue of their form, encode declarations, while declaratives can express commands only via implicatures. Maljaars et al. (2011) found that among three forms of communication, namely behavior regulation, social interaction, and joint attention, the proportion of the first to the third was much higher in children with autism than in typically developing children, who showed the opposite pattern. The non-verbal group with autism did not or barely communicate for declarative purposes and used the least complex forms of communication.

Part and parcel of the general problems with deixis are classical misuses of pronouns, as in the non-shifted pronoun use 
resulting from echolalia but also the spontaneous substitutions of non-standard grammatical Persons for where personal (1st or 2nd) forms would be expected. In a recent corpus-based study of two French-speaking autistic children, Dascalu (2014) found that non-standard (2nd and 3rd) personal forms of selfreference and the normally expected 1st personal forms can seem context-equivalent to the autistic children. One child used French "il" ("he") as a "passe-partout" referential device fitting all objects of reference equally. Grammatical Person was not merely distorted, moreover, but there is a distinctive Person-shift from personal to 3 rd-personal forms for self-reference, while the reverse is not the case. As these findings suggest, not use of pronouns as such is impaired, but grammatical Person is. This does not appear to be the consequence of a general problem in "perspective-taking" in some non-linguistic sense, since the children did take the perspectives of others, as in numerous examples documenting that they are pursuing the trains of thoughts of others, imitate others, and role-play. The Person shift in its grammatical dimension is also confirmed by numerous earlier studies showing a preference of 3 rd Personal forms of selfreference (such as the child's own proper name) in both spoken (Jordan, 1989; Lee and Hobson, 1994; Mizuno et al., 2011) and signed language (Shield and Meier, 2014); and by the fact that it does not occur in isolation but as part of a larger disturbance in the referential use of language. Thus Modyanova (2009) showed, in a comparison of indefinite NPs (e.g., "an/another apple") with definite NPs ("the/that apple"), that children with autism compared with Asperger's or Pervasive Developmental Disorder

\section{References}

Alcantara, J. I., Weisblatt, E. J., Moore, B. C., and Bolton, P. F. (2004). Speechin-noise perception in high-functioning individuals with autism or Asperger's syndrome. J. Child Psychol. Psychiatry 45, 1107-1114. doi: 10.1111/j.14697610.2004.t01-1-00303.x

Baron-Cohen, S. (1988). Social and pragmatic deficits in autism: cognitive or affective? J. Autism Dev. Disord. 18, 379-402. doi: 10.1007/BF02212194

Cartmill, E. A., Hunsicker, D., and Goldin-Meadow, S. (2014). Pointing and naming are not redundant: children use gesture to modify nouns before they modify nouns in speech. Dev. Psychol. 50, 1660-1666. doi: 10.1037/a00 36003

Curtin, S., and Vouloumanos, A. (2013). Speech preference is associated with autistic-like behavior in 18-months-olds at risk for Autism Spectrum Disorder. J. Autism Dev. Disord. 43, 2114-2120. doi: 10.1007/s10803-013-1759-1

Dascalu, C. (2014). First-person Referents in Typical and Autistic Usage: Semantic, Pragmatic and Cognitive Perspectives, Doctoral Dissertation, Université Sorbonne Nouvelle Paris 3.

DeVilliers, J. (2007). The interface of language and theory of mind. Lingua 117, 1858-1878. doi: 10.1016/j.lingua.2006.11.006

Eigsti, I. M., Bennetto, L., and Dadlani, M. (2007). Beyond pragmatics: Morphosyntactic development in autism. J. Autism Dev. Disord. 37, 1007-1023. doi: 10.1007/s10803-006-0239-2

Happé, F., and Frith, U. (2009). The beautiful otherness of the autistic mind. Philos. Trans. R. Soc. Lond. B Biol. Sci. 364, 1345-1350. doi: 10.1098/rstb.2009.0009

Hauser, M. D. (1996). The Evolution of Communication. Cambridge, MA: MIT Press.

Hinzen, W., and Sheehan, M. (2013). The Philosophy of Universal Grammar. Oxford: Oxford University Press.

Hobson, R. P., García-Peérez, R. M., and Lee, A. (2010). Person-centred (deictic) expressions and autism. J. Autism Dev. Disord. 40, 403-415. doi: 10.1007/s10803-009-0882-5
(PDD-NOS) showed no knowledge of definite determiners at all (Lord and Rutter, 1994).

In sum, the evidence synthesized here suggests a seismic shift in grammar-based semantics and the deictic space in which all thought, speech, and reference takes place. The language change we see concerns core linguistic functions that depend on specific forms of grammatical organization, such as Person, determiners, or sentential complexity, though to different degrees. These functions mediate cognitive ones, and they specifically concern how language normally mediates a species-specific deictic frame. It is not clear which nonlinguistic deficit would account for this change, when it is linguistically highly specific, and ToM in particular has itself long been noted to be strongly correlated with language in its explicit form (DeVilliers, 2007; Paynter and Peterson, 2010). This motivates casting a novel linguistic eye on mental change, in line with recent developments in linguistic theory that see linguistic organization as a central principle for a human-specific cognitive type and self (Hinzen and Sheehan, 2013).

\section{Acknowledgments}

Funding was obtained from the Arts and Humanities Research Council Grant AH/L004070/1 ("Language and Mental Health") and the grant FFI2013-40526P ("Language and the Disordered Mind") of the Ministerio de Economía y Competitividad, Madrid.

Hobson, R. P., and Meyer, J. A. (2005). Foundations for self and other: a study in autism. Dev. Sci. 8, 481-491. doi: 10.1111/j.1467-7687.2005.00439.x

Humphries, T., Kushalnagar, P., Mathur, G., Napoli, D. J., Padden, C., and Rathmann, C. (2014). Ensuring language acquisition for deaf children. Language 90, 31-52. doi: 10.1353/lan.2014.0036

Jordan, R. R. (1989). An experimental comparison of the understanding and use of speaker addressee personal pronouns in autistic children. Br. J. Disord. Commun. 24, 169-179. doi: 10.3109/13682828909011954

Kjelgaard, M. M., and Tager-Flusberg, H. (2001). An investigation of language impairment in autism: implications for genetic subgroups. Lang. Cogn. Process. 16, 287-308. doi: 10.1080/01690960042000058

Klin, A. (1991). Young autistic children's listening preferences in regard to speech: a possible characterization of the symptom of social withdrawal. J. Autism Dev. Disord. 21, 29-42. doi: 10.1007/BF02206995

Kujala, T., Lepistob, T., and Naatanen, R. (2013). The neural basis of aberrant speech and audition in autism spectrum disorders. Neurosci. Biobehav. Rev. 37, 697-704. doi: 10.1016/j.neubiorev.2013.01.006

Lee, A., and Hobson, R. P. (1994). I, You, Me, and Autism: an experimental study. J. Autism Dev. Disord. 24, 155-176. doi: 10.1007/BF02172094

Lord, C., and Paul, R. (1997). "Language and communication in autism," in Handbook of Autism and Pervasive Development Disorders, 2nd Edn., eds D. J. Cohen and F. R. Volkmar (New York, NY: Wiley), 195-225.

Lord, C., Risi, S., and Pickles, A. (2004). "Trajectory of language development in autistic spectrum disorders," in Developmental Language Disorders: From Phenotypes to Etiologies, eds M. L. Rice and S. F. Warren (Mahwah, NJ: Erlbaum), 7-30.

Lord, C., and Rutter, M. (1994). "Autism and pervasive developmental disorders," in Child and Ado- lescent Psychiatry: Modern approaches, 3rd Edn., eds M. Rutter, L. Hersov, and E. Taylor (Oxford: Blackwell), 569-593.

Loveland, K., Landry, S., Hughes, S., Hall, S., and McEvoy, R. (1988). Speech acts and the pragmatic deficits of autism. J. Speech Hear. Res. 31, 593-604. doi: 10.1044/jshr.3104.593 
Maljaars, J., Noens, I., Jansen, R., Scholte, E., and van Berckelaer-Onnes, I. (2011). Intentional communication in nonverbal and verbal lowfunctioning children with autism. J. Commun. Disord. 44, 601-614. doi: 10.1016/j.jcomdis.2011.07.004

Mandy, W., and Skuse, D. (2008). What is theassociation between the socialcommunication element of autism and repetitive interests, behaviours and activities? J. Child Psychol. Psychiatry 49, 795-808. doi: 10.1111/j.14697610.2008.01911.x

Mizuno, A., Liu, Y., Williams, D. L., Keller, T. A., Minshew, N. J., and Just, M. A. (2011). The neural basis of deictic shifting in linguistic perspective-taking in high-functioning autism. Brain 134:8. doi: 10.1093/brain/awr151

Modyanova, N. (2009). Semantic and Pragmatic Language Development in Typical Acquisition, Autism Spectrum Disorders, and Williams Syndrome with Reference to Developmental Neurogenetics of the Latter. Ph.D. dissertation, Massachusetts Institute of Technology.

Mundy, P., and Markus, J. (1997). On the nature of communication and language impairment in autism. Ment. Retard. Dev. Disabil. Res. Rev. 3, 343-349.

Mundy, P., Sigman, M., and Kasari, C. (1990). A longitudinal study of joint attention and language development in autistic children. J. Autism Dev. Disord. 20, 115-128. doi: 10.1007/BF02206861

Paynter, J., and Peterson, C. (2010). Language and ToM development in autism versus Asperger syndrome: Contrasting influences of syntactic versus lexical/semantic maturity. Res. Autism Spectr. Disord. 4, 377-385. doi: 10.1016/j.rasd.2009.10.005

Penn, D. C., Holyoak, K. J., and Povinelli, D. J. (2008). Darwin's mistake. Behav. Brain Sci. 31, 109-130. doi: 10.1017/S0140525X08003543

Peppe, S., McCann, J., Gibbon, F., O'Hare, A., and Rutherford, M. (2007). Receptive and expressive prosodic ability in children with high-functioning autism. J. Speech Lang. Hear. Res. 50, 1015-1028. doi: 10.1044/10924388(2007/071)

Pierce, S., and Bartolucci, G. (1977). A syntactic investigation of verbal autistic, metally retarded, and normal children. J. Autism Child. Schizophr. 7, 2. doi: 10.1007/BF01537724

Rapin, I., and Dunn, M. (2003). Update on the language disorders of individuals on the autistic spectrum. Brain Dev. 25, 166-172. doi: 10.1016/S03877604(02)00191-2

Schaller, S. (2012). A Man Without Words. Berkeley, CA: University of California Press.
Shield, A., and Meier, R. P. (2014). "Personal pronoun avoidance in deaf children with autism," in Proceedings of the 38th Annual Boston University Conference on Language Development, (Somerville, MA: Cascadilla Press), 403-415.

Tager-Flusberg, H. (1981). On the nature of linguistic functioning in early infantile Autism. J. Autism Dev. Disord. 11, 45-56. doi: 10.1007/BF01531340

Tager-Flusberg, H. (1996). Current theory and research on language and communication in autism. J. Autism Dev. Disord. 26, 169-172. doi: 10.1007/BF02172006

Tager-Flusberg, H. (2006). Defining language phenotypes in autism. Clin. Neurosci. Res. 6, 219-224. doi: 10.1016/j.cnr.2006.06.007

Tager-Flusberg, H., Joseph, R., and Folstein, S. (2001). Current directions in research on autism. Ment. Retard. Dev. Disabil. Res. Rev. 7, 21-29. doi: 10.1002/1098-2779(200102)7

Tager-Flusberg, H., and Joseph, R. M. (2003). Identifying neurocognitive phenotypes in autism. Philos Trans R Soc Lond B Biol Sci. 358, 303-314. doi: 10.1098/rstb.2002.1198

Tattersall, I. (2008). The World from Beginnings to 4000 BCE. Oxford: Oxford University Press.

Tattersall, I. (2014). An evolutionary context for the emergence of language. Lang. Sci. 46, 199-206. doi: 10.1016/j.langsci.2014.06.011

Tomasello, M. (2008). The Origins of Human Communication. Cambridge, MA MIT Press.

Vouloumanos, A., Martin, A., and Onishi, K. H. (2014). Do 6-montholds understand that speech can communicate? Dev. Sci. 17, 1-8. doi: $10.1111 /$ desc. 12170

Vouloumanos, A., and Waxman, S. R. (2014). Listen up! Speech is for thinking during infancy. Trends Cogn. Sci. 18, 642-646. doi: 10.1016/j.tics.2014.10.001

Conflict of Interest Statement: The authors declare that the research was conducted in the absence of any commercial or financial relationships that could be construed as a potential conflict of interest.

Copyright (c) 2015 Hinzen, Rosselló, Mattos, Schroeder and Vila. This is an openaccess article distributed under the terms of the Creative Commons Attribution License (CC BY). The use, distribution or reproduction in other forums is permitted, provided the original author(s) or licensor are credited and that the original publication in this journal is cited, in accordance with accepted academic practice. No use, distribution or reproduction is permitted which does not comply with these terms. 